\title{
Typing of Streptococcus pyogenes by pyrolysis mass spectrometry
}

\author{
J. T. MAGEE, J. M. HINDMARCH* and C. D. NICOL* \\ Department of Microbiology, Children's Hospital, Sheffield S10 2TH and "Department of Bacteriology, Royal \\ Hallamshire Hospital, Sheffield S10 2JF
}

\begin{abstract}
Summary. Strains of Streptococcus pyogenes from an outbreak in an oncology ward (13) and routine isolates from sporadic cases (6) were examined blind by pyrolysis mass spectrometry (Py-MS), extending previous work on epidemiological typing. This outbreak appeared more complex than one reported previously, but Py-MS and conventional typing results were in complete agreement. The results confirm the potential of Py-MS as a rapid method for identification at strain level in studies of cross infection.
\end{abstract}

\section{Introduction}

Streptococcus pyogenes is a virulent organism; it can cause outbreaks of infection that are particularly serious in susceptible patients such as those in oncology or burns units. Epidemiological typing of strains has depended upon serotyping of $\mathbf{M}$ and $\mathbf{T}$ antigens. Although this is laborious, the serotyping differentiates strains at a fine level, probably finer than typing systems for many other species. In a previous study of $S$. pyogenes isolates from an outbreak in a burns unit, ${ }^{1}$ pyrolysis mass spectrometry (Py-MS) clearly differentiated outbreak strains from other strains of the same species. Unlike most classical typing procedures, $\mathbf{P y}$ MS is rapid and the process of strain comparison excludes the concept of non-typable strains. An outbreak of $S$. pyogenes infection in an oncology ward offered the opportunity for a further study of Py-MS typing.

\section{Materials and methods}

The strains examined comprised 13 isolates from the outbreak and six other routine isolates (table); all were $\beta$-haemolytic streptococci of Lancefield's group A, susceptible to erythromycin and tetracycline. One outbreak strain was duplicated, giving a blind coded set of 20 strains for Py-MS analysis. Pyrolysis methods and materials were as used previously. ${ }^{1}$ Strains were typed by conventional methods at the Streptococcus Reference Laboratory, Central Public Health Laboratory, London.

\section{Results}

\section{The outbreak}

Infections occurred in seven patients (one wound, two throat, two chest, one urine, two vaginal; patients

Received 8 June 1990; accepted 6 March 1991
PA-PG). S. pyogenes was isolated from a wound swab from patient PE, probably the index case, on 5 March 1990 (table); the further infections with $S$. pyogenes in patients, and carriage (one throat, one nose; staff S1, S2) in staff were found in the subsequent 2 weeks. Environmental swabs yielded a further two isolates $(\mathrm{X} 1, \mathrm{X} 2)$, both from patient toilets. Control measures were instituted to terminate the outbreak. In the absence of typing data, it was initially assumed that all strains isolated were from the same source, and that carriage by staff was a factor in the spread.

\section{Py-MS typing}

A dendrogram derived from Py-MS data (figure) showed two tightly homogeneous clusters, one of 13 isolates (cluster A) and the other of two isolates (B), with intra-cluster similarities of $\chi^{2}<35$ on $19 \mathrm{df}$ ( $\mathrm{p}<$ 0.005 that isolates were indistinguishable in Py-MS). Cluster A contained both examples of the duplicated outbreak strain. The remaining five strains were clearly dissimilar from one another, and from the members of the two tight clusters $\left(\chi^{2}>65, p \ll 0 \cdot 0001\right)$.

These similarities proved to be compatible with the origin of strains when the blind code was broken, and with the results of conventional typing, received later. Cluster A comprised all isolates of $M$ type 75 , $T$ type 25 , opacity factor $(\mathrm{OF})+$. These were associated with the outbreak, with one exception (R1), an isolate submitted by a general practitioner from a patient with a throat infection. Further investigation showed that $\mathrm{R} 1$ was from a community health worker who may have had contact with the infected patients.

Cluster B comprised two M12 T12 OF - isolates, both from nasal swabs of staff member S2. Although initially thought to be part of the outbreak, these isolates were clearly distinct from those of cluster $A$ in conventional typing and Py-MS.

The remaining strains were isolated routinely and, although clearly distinct in Py-MS, tended to form 
Table. Strain origins and typing results

\begin{tabular}{|c|c|c|c|c|c|c|c|}
\hline \multirow{2}{*}{ Strain* } & \multirow{2}{*}{ Patient $\dagger$} & \multirow{2}{*}{ Source } & \multirow{2}{*}{$\begin{array}{l}\text { Infection } \\
\text { or } \\
\text { carriage }\end{array}$} & \multicolumn{3}{|c|}{ Conventional typing $\ddagger$} & \multirow{2}{*}{$\begin{array}{l}\text { Py-MS } \\
\text { cluster }\end{array}$} \\
\hline & & & & $\mathbf{M}$ & $\mathrm{T}$ & OF & \\
\hline Ol & PA & Throat & Infection & 75 & 25 & + & A \\
\hline $\mathrm{O} 2$ & PB & Sputum & Infection & 75 & 25 & + & A \\
\hline $\mathrm{O} 3$ & PC & Sputum & Infection & 75 & 25 & + & A \\
\hline $\mathrm{O} 4$ & PD & Urine & Infection & 75 & 25 & + & A \\
\hline O5 & $\mathrm{X} 1$ & Toilet & & 75 & 25 & + & A \\
\hline O6 & PE & Wound & Infection & 75 & 25 & + & A \\
\hline O7 & S1 & Throat & Carriage? & 75 & 25 & + & A \\
\hline Ol rpt & & & & & & & A \\
\hline R1 & $\mathbf{R P}$ & Throat & Infection & 75 & 25 & + & A \\
\hline $\mathrm{O} 8$ & $\mathrm{X} 2$ & Toilet & & 75 & 25 & + & A \\
\hline O9 & PF & Genital & Infection & 75 & 25 & + & A \\
\hline $\mathrm{O} 10$ & PD & Throat & Infection & 75 & 25 & + & A \\
\hline O11 & PG & Genital & Infection & 75 & 25 & + & A \\
\hline $\mathrm{R} 2$ & RQ & Skin & Infection & 3 & $\mathrm{nt}$ & - & $\ldots$ \\
\hline $\mathrm{O} 12$ & $\mathrm{~S} 2$ & Nose & Carriage & 12 & 12 & - & B \\
\hline $\mathrm{O} 13$ & S2 & Nose & Carriage & 12 & 12 & - & B \\
\hline R3 & $\mathrm{RR}$ & Blood & Infection & 12 & 12 & - & $\ldots$ \\
\hline R4 & RS & Throat & Infection & - & B3264 & + & $\ldots$ \\
\hline R5 & RT & Ear & Infection & 3 & 3 & - & $\ldots$ \\
\hline R6 & RU & Throat & Infection & 3 & 3 & - & $\ldots$ \\
\hline
\end{tabular}

* Strains are listed in dendrogram order (figure). An $\mathrm{O}$ prefix indicates an outbreak isolate, and an $\mathrm{R}$ prefix indicates a routine isolate. One isolate, $\mathrm{Ol}$, was analysed in duplicate in Py-MS, and the second example, O1 rpt, is listed without details of source or conventional typing results.

$\dagger \mathrm{P}, \mathrm{S}$ and $\mathrm{X}$ indicate outbreak investigation isolates from patients, staff or environmental sites respectively. An R prefix indicates a routine isolate.

$\ddagger$ nt, non-typable.

$\mathrm{X}^{2}(19 \mathrm{df})$ of strains being indistinguishable in Py-MS

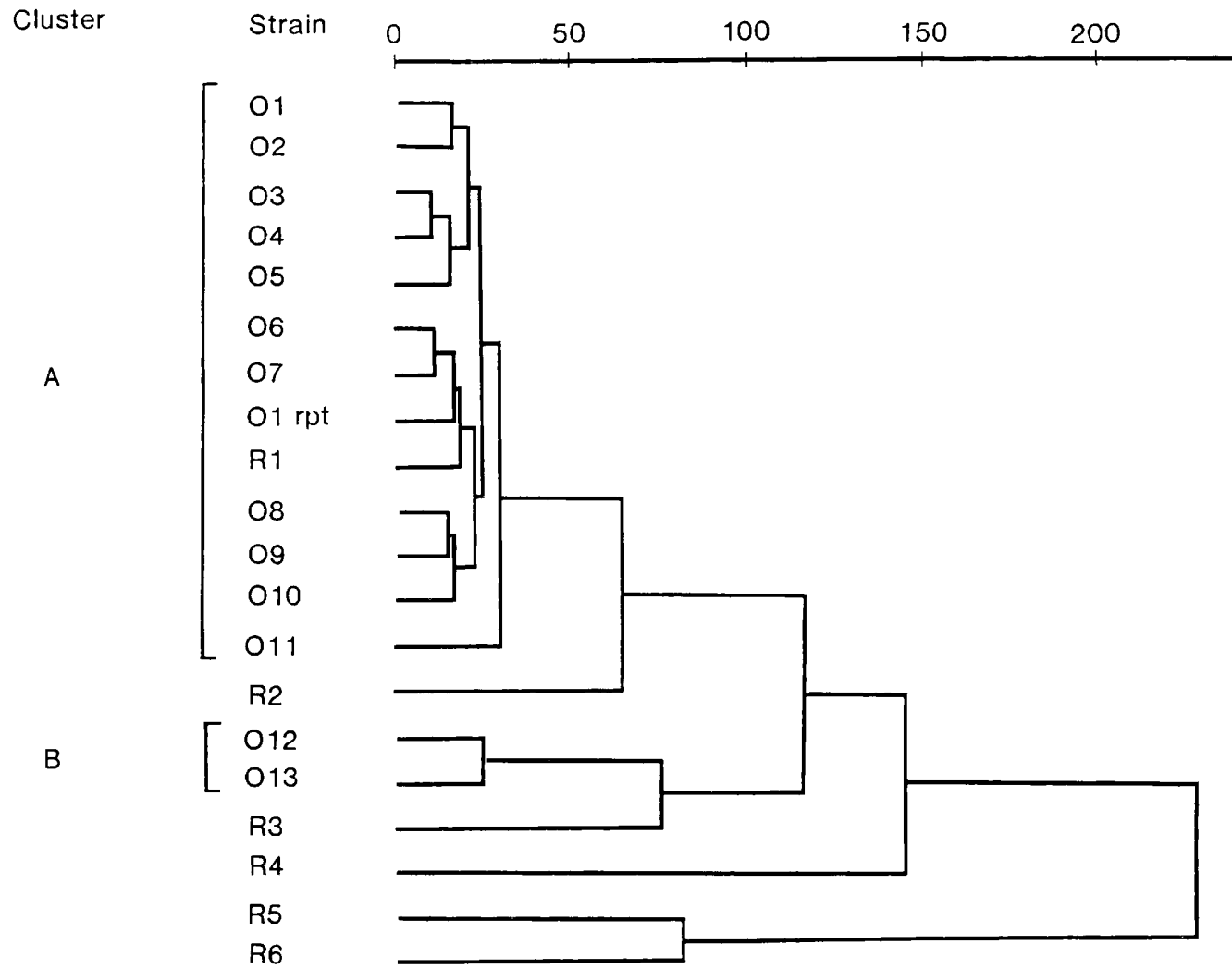

Figure. A dendrogram indicating inter-strain similarities in Py-MS. Strain designations are as in the table, in which the strains are listed in dendrogram order. 
loose clusters with similar conventional typing patterns. For example, the two M3 T3 OF - strains (R5, R6) were more similar to one another than to the remainder of the study strains, as were the three M12 T12 OF - strains. Nonetheless, Py-MS clearly distinguished the sporadic strains in these loose clusters. This discrimination of strains with identical $M$ and $T$ antigens implies that Py-MS has higher resolution than conventional typing.

\section{Discussion}

In previous Py-MS studies, isolates from an outbreak of $S$. pyogenes M22 T12 infection were clearly distinct from sporadic strains, ${ }^{1}$ collection strains of Candida albicans could be identified at strain level ${ }^{2}$ and isolates of Haemophilus ducreyi found in an outbreak in Sheffield were clearly distinct from other strains of this species isolated worldwide (Magee, Hindmarch and Duerden, unpublished data). Freeman et al. ${ }^{3}$ also found tight Py-MS clusters corresponding to isolates from outbreaks of Salmonella enteritidis phage type 4 and $S$. pyogenes M49 T14 that were clearly distinct from sporadic strains.

Speed, convenience and low running costs make Py-MS an attractive method for the investigation of outbreaks, and evidence is increasing that this method may be applicable with little or no modification to other microbial species. Py-MS differs from earlier typing techniques in that isolates may be compared on the basis of a statistical probability that they are indistinguishable.

\section{References}

1. Magee JT, Hindmarch JM, Burnett IA, Pease A. Epidemiological typing of Streptococcus pyogenes by pyrolysis mass spectrometry. J Med Microbiol 1989; 30: 273-278.

2. Magee JT, Hindmarch JM, Duerden BI, Mackenzie DWR.
Values of $p>0.001$ seem to indicate recent common ancestry in our studies. This is lower than the normally accepted significance level of 0.05 , probably because inter-strain discriminant analysis exaggerates differences between identical isolates, by including small random sample specific differences between their replicate spectra sets. However, the dissimilarity between different strains has invariably been greater than any contribution from this effect in our studies.

The probability is based on quantitative data that reflect overall cell composition and therefore many chemical features, rather than the presence or absence of small number of specific chemical receptors, phage or bacteriocin receptors, antigens, etc. The concept of a type, i.e., a group of strains that give identical results for a small range of such receptors, but are not necessarily of recent common lineage, may not apply to Py-MS data. ${ }^{1}$ Indeed, there is some evidence from this and other studies that Py-MS can discriminate at a finer level than classical methods. Equally, Py-MS cannot yield a "not typable" result.

This blind study confirms the potential of Py-MS in the epidemiology of outbreaks. The structure of this strain collection was more complex than in the previous study, but the results again demonstrate clear agreement of epidemiological and conventional typing information with the Py-MS results.

We thank the Streptoccus Reference Laboratory, Central Public Health Laboratory, Colindale Ave., London for typing the strains in conventional tests.

Pyrolysis mass spectrometry as a method for inter-strain discrimination of Candida albicans. J Gen Microbiol 1988; 134: 2841-2847.

3. Freeman R, Goodfellow M, Gould FK, Hudson SJ, Lightfoot WF. Pyrolysis-mass spectrometry (Py-MS) for the rapid epidemiological typing of clinically significant bacterial pathogens. J Med Microbiol 1990; 32: 283-286. 